\title{
Arterial Stiffness and Cardiovascular Therapy
}

\author{
Miodrag Janić, Mojca Lunder, and Mišo Šabovič \\ Department of Vascular Diseases, University of Ljubljana Medical Centre, Zaloška 7, SI 1000 Ljubljana, Slovenia \\ Correspondence should be addressed to Miodrag Janić; miodrag.janic@kclj.si
}

Received 20 June 2014; Revised 14 July 2014; Accepted 14 July 2014; Published 7 August 2014

Academic Editor: Alice Santos-Silva

Copyright (C) 2014 Miodrag Janić et al. This is an open access article distributed under the Creative Commons Attribution License, which permits unrestricted use, distribution, and reproduction in any medium, provided the original work is properly cited.

\begin{abstract}
The world population is aging and the number of old people is continuously increasing. Arterial structure and function change with age, progressively leading to arterial stiffening. Arterial stiffness is best characterized by measurement of pulse wave velocity (PWV), which is its surrogate marker. It has been shown that PWV could improve cardiovascular event prediction in models that included standard risk factors. Consequently, it might therefore enable better identification of populations at high-risk of cardiovascular morbidity and mortality. The present review is focused on a survey of different pharmacological therapeutic options for decreasing arterial stiffness. The influence of several groups of drugs is described: antihypertensive drugs (angiotensinconverting enzyme inhibitors, angiotensin receptor blockers, calcium channel blockers, beta-blockers, diuretics, and nitrates), statins, peroral antidiabetics, advanced glycation end-products (AGE) cross-link breakers, anti-inflammatory drugs, endothelin-A receptor antagonists, and vasopeptidase inhibitors. All of these have shown some effect in decreasing arterial stiffness. Nevertheless, further studies are needed which should address the influence of arterial stiffness diminishment on major adverse cardiovascular and cerebrovascular events (MACCE).
\end{abstract}

\section{Introduction}

The world population is aging so the number of old people is continuously increasing $[1,2]$. With increasing age, arterial structure and function change, progressively leading, among other deteriorations, to arterial stiffening $[3,4]$. One of the most important parameters most commonly measured and understood, being also the best surrogate for arterial stiffness, is pulse wave velocity (PWV) [5-7]. In a recent meta-analysis, aortic PWV was found to improve cardiovascular event prediction in models that included standard risk factors (arterial hypertension, smoking, diabetes, etc.) and might therefore enable better identification of high-risk populations $[8,9]$. Even though this data exists, there is still no pharmacological approach regularly used in clinical practice aiming to decrease arterial stiffness. In other words, the therapeutic approach does not aim at arterial stiffness decrease per se. Although evidence of the importance of PWV is growing, there was no study reported in which a decrease of cardiovascular mortality due to reducing arterial stiffness by pharmacologic approaches had been observed. Nevertheless, we believe that there is sufficient proof of PWV being an important cardiovascular risk factor and that such a study is very much needed. Therefore, in what follows we review all known pharmacological approaches capable of decreasing arterial stiffness. Importantly, it should be noted that the effects of pharmacologic agents on stiffness are usually slight or modest, but not substantial. Thus, new therapeutic approaches to decrease arterial stiffness are highly desirable.

\section{Pathophysiological Aspects of Arterial Stiffness}

Conductive arteries propel the pressure wave generated by the heart, that is, the ejection of blood from the left ventricle. This wave is reflected at the impedance mismatch points (junctions of large conduit arteries, high-resistance arteries, and bifurcations), from where it travels backwards to the heart. Consequently, the observed generated wave is the sum of the forward travelling wave (moving from the heart) and the reflected wave (travelling backwards towards the heart) [10]. In young healthy subjects who have compliant arteries the reflected waves return to the ascending aorta at the 
time of diastole, thus leading to pressure amplification in this part of cardiac cycle, leading to an increase in diastolic blood pressure (DBP) [11]. As pulse waves travel faster in stiffer arteries, PWV measurement is consequently the best surrogate for arterial stiffness evaluation in everyday practice. It also increases with age and is a predictor of cardiovascular risk. It has been calculated that an increase in PWV by $1.0 \mathrm{~m} / \mathrm{s}$ increases the risk of cardiovascular events by $14 \%$ [12].

The low blood pressure elastic modulus of the elastin component of arterial media dominates the mechanical behavior of the arterial wall, making it distensible [10]. At higher blood pressures, the wall is less extensible, due to the low elastic modulus of the collagen component of the arterial media that dominates at these pressures [13]. It can be concluded that at low blood pressures a small amount of collagen fibers is recruited. When the blood pressure rises, more and more collagen fibers are engaged, the elastin component having relatively less influence, leading to sufficient support of the arterial wall and stabilization of aortic root distension. To sum up, arterial wall compliance and distensibility progressively decrease with increasing blood pressure. Blood pressure-dependent changes in elastic modulus are nonlinear; that is, the change in elastic properties is much greater at high blood pressures than at low blood pressures [10]. Blood pressure increase leads to PWV increase. The consequence is pressure wave propagation, which is a result of the increase in amplitude of the wave travelling from the heart. It means that the top of the wave travels faster than the rest of the wave. This leads to the physiological findings of a consistent difference between blood pressure values in the ascending aorta and brachial artery. In young healthy subjects, the difference between pulse pressure (PP) and systolic blood pressure (SBP) in the ascending aorta and at the level of brachial artery can be as much as $20 \mathrm{mmHg}$, while in patients treated for hypertension it is considerably lower (6 to $11 \mathrm{mmHg}$ ) [11].

The arteries become stiffer with increasing age and disease (e.g., hypertension, chronic kidney disease, diabetes, and atherosclerosis). Increased stiffness results from structural changes, such as fragmentation of elastin, an increased amount of collagen, arterial calcification, glycation of both elastin and collagen, and cross-linking of collagen by advanced glycation end- products (AGE) [14-17]. These changes could be measured quantitatively in the pathology department. On the other hand, clinical evaluation of arterial mechanical properties is far more complex and a complete description of the strain-stress relationship in vivo is not possible due to uncertainties arising from nonlinear behavior, viscoelasticity, anisotropy, active tone, residual stresses, and tethering [18]. The methods most commonly used measure transit times between different sites in the arterial tree and calculate arterial PWV and measure local arterial compliance, the distensibility or stiffness index, and also the augmentation index (Aix) [19].

Increased arterial stiffness leads to increased PWV and central arterial pressure, resulting in higher arterial pulsatility. The latter leads to damage of the microcirculation in several organs, especially the highly perfused ones, such as myocardium, the kidneys, and brain (Figure 1). Taking into account that the population is aging, stiffness is an important factor in pathophysiological aspects [20].

\section{Endothelial Function and Arterial Stiffness}

Endothelial function and arterial stiffness are two different aspects of arterial disease, which are interconnected as their pathophysiological background is similar. Nitric oxide (NO) has been shown to contribute importantly to arterial compliance or distensibility [21]. Arterial stiffness can be regarded as composed of two distinct components: a structural and a dynamic component. These two are obviously interconnected. The structural component is represented by the collagen and elastin fibers in arterial media, as well as other connecting molecules [22]. The dynamic component is represented by the tone of smooth muscle cells, also in the arterial media. This tone is dependent on vasoactive substances released from the endothelium [23]. As mentioned above, the artery becomes stiffer due to an increase in the collagen-elastin ratio. On the other hand, the stiffer the artery gets, the greater the hemodynamic load to which its endothelium is exposed, resulting in its earlier damage. The dynamic and structural components of arterial stiffness are interconnected and lead to a vicious cycle (Figure 2).

\section{Influence of Drugs on Arterial Stiffness}

According to the literature, several drugs have been shown to influence arterial stiffness: antihypertensives, statins, peroral antidiabetics, AGE cross-link breakers, anti-inflammatory drugs, endothelin-A receptor antagonists, and vasopeptidase inhibitors. The majority of them act predominantly on the dynamic component of arterial stiffness and to a lesser extent on the structural component in arterial wall remodeling, whereas only AGE cross-link breakers act directly on the structural component. Influence of particular drugs or drug groups on arterial stiffness is summarized in Table 1.

4.1. Antihypertensive Drugs. Antihypertensive drugs have been implicated in arterial stiffness diminishment but vary in their degree of effect. The various antihypertensive drug classes have been more or less extensively evaluated in this regard. Unequivocally, the renin-angiotensin system inhibitors proved to be superior to all other antihypertensive drugs in reducing arterial stiffness. There are different reasons for and understanding of this phenomenon, but the most probable explanation lies in the profibrotic action of the renin-angiotensin system, as the turnover of the extracellular matrix in the arterial wall per se leads to a change in the properties of the vessel [24]. In what follows, antihypertensive drugs are listed according to the amount of evidence and their effect on arterial stiffness.

4.1.1. Angiotensin-Converting Enzyme Inhibitors. There had been some evidence that angiotensin-converting enzyme (ACE) inhibitors lead to arterial compliance improvement [25], but it was the REASON (pREterax in regression of Arterial Stiffness in a contrOlled double-bliNd) study 


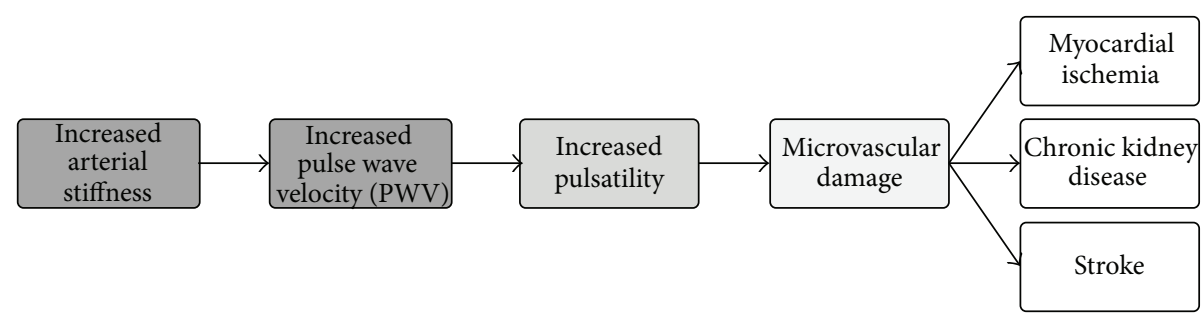

FIGURE 1: Flowchart describing the effect of increased arterial stiffness on end organ damage.

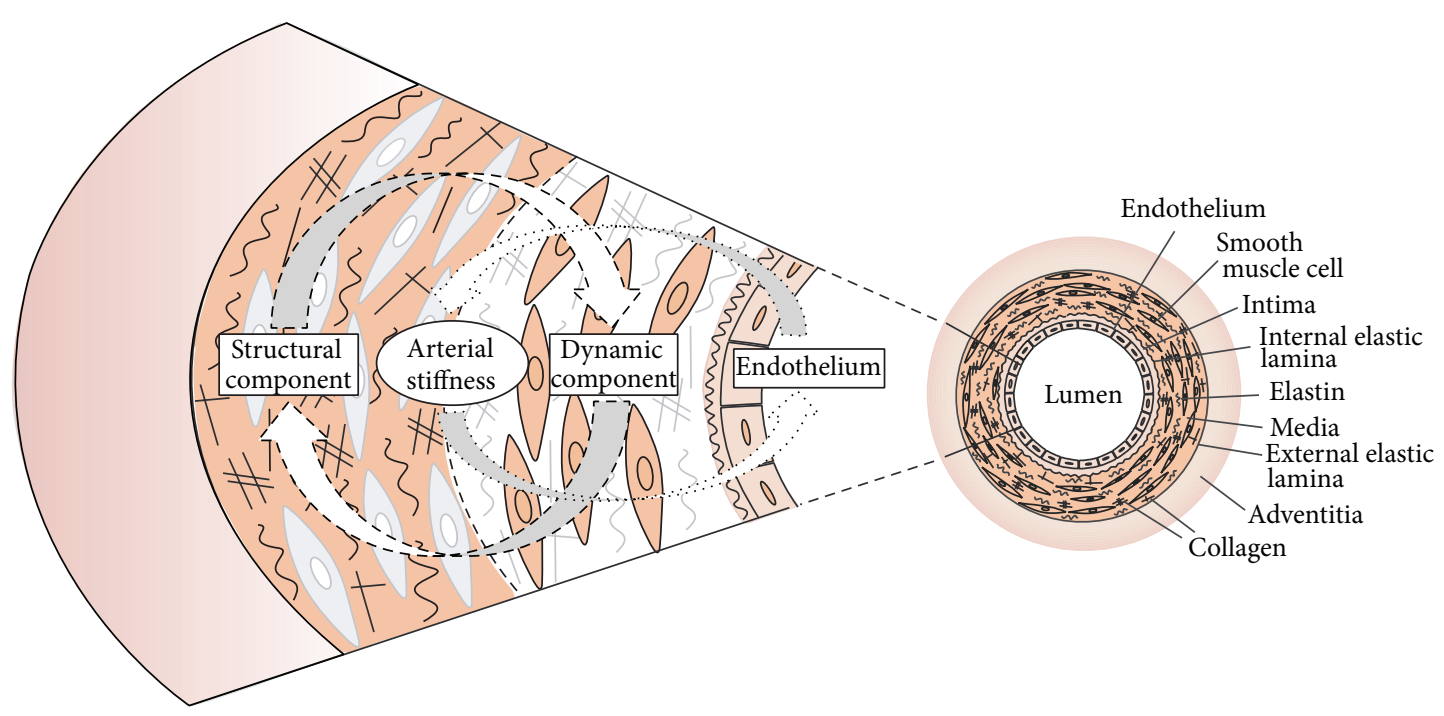

FIGURE 2: Vicious cycle-the connection between the dynamic and structural components of arterial stiffness.

that first evaluated the long-term influence of these drugs on arterial stiffness. This study was performed using the perindopril/indapamide combination and compared it to the use of atenolol. The former combination proved to be more efficacious in reducing systolic blood pressure as well as pulse pressure. The effect was more pronounced in the central indices. Interestingly, PWV showed a similar reduction in both groups, while on the other hand Aix was more significantly reduced in the combination group. The effect obtained in the combination group lasted even after 9 months of treatment without additional blood pressure reduction $[26,27]$. In the ADVANCE (Action in Diabetes and Vascular Disease: Preterax and Diamicron Modified Release Controlled Evaluation) trial, the same combination of perindopril/indapamide was also evaluated, and it was this study that proved the importance of arterial stiffness and its association with cardiovascular risk [28]. The effect of ACE inhibitors on pulsatile hemodynamics in patients with stable coronary artery disease was evaluated in the PEACE (Prevention of Events with Angiotensin-Converting Enzyme Inhibition) substudy. This study showed that trandolapril moderately decreased PWV, beyond expectations and without relation to blood pressure reduction. Nevertheless, no improvement in aortic compliance or decrease in Aix was observed [29]. All the studies described were long-term studies, but even some short (evaluating acute effects) to medium (less than 6 months) term studies showed a reduction of arterial stiffness when ACE inhibitors were used [30]. These effects were obtained for most drugs in this class, that is, captopril [31], perindopril [32], trandolapril [29], enalapril [33], lisinopril [34], ramipril [35], quinapril $[31,36]$, and fosinopril [37]. These effects were attributed to the ACE inhibitors' capability of chronically reducing remodeling of the small arteries, leading to reduction of reflection coefficients.

4.1.2. Angiotensin Receptor Blockers. Intuitively, it might be expected that angiotensin receptor blockers (ARBs or sartans) would produce the same effect as ACE inhibitors. In a trial with patients with resistant hypertension who were receiving three antihypertensive drugs in maximal dosages, including ACE inhibitors, the addition of valsartan for two weeks resulted in reduction of Aix [41]. When valsartan was compared to captopril, the two drugs equally reduced PWV as well as Aix [42]. As far as Aix reduction is concerned, losartan (see the LIFE (Losartan Intervention For Endpoint reduction in hypertension) [43] and OPTIMAAL (Optimal Trial in Myocardial Infarction with Angiotensin Antagonist Losartan) [44] studies) and candesartan [45, 46] were proven to reduce it. Other ARBs, such as valsartan (the VALUE (Valsartan Antihypertensive Long-Term Use Evaluation) study) [47-49], olmesartan [50], telmisartan [51], and eprosartan 
TABLE 1: Influence of particular drugs or drug groups on arterial stiffness. Uniform effect-the drug or drug group definitely improves arterial stiffness; prevailing effect-the drug or drug group improves arterial stiffness in the majority of studies; conflicting effect-the drug or drug group effect is homogeneously distributed between improving arterial stiffness or not; neutral effect-the drug or drug group does not influence arterial stiffness.

\begin{tabular}{|c|c|c|c|}
\hline $\begin{array}{l}\text { Effect on arterial stiffness } \\
\text { reduction/improvement }\end{array}$ & Drug group & Drug class/drug & References \\
\hline \multirow{6}{*}{ Uniform effect } & \multirow{4}{*}{ Antihypertensive } & Angiotensin converting enzyme inhibitors & {$[25-40]$} \\
\hline & & Angiotensin receptor blockers & {$[38,40-54]$} \\
\hline & & Calcium channel blockers & {$[32,34,37,46,49,55-60]$} \\
\hline & & Aldosterone antagonists-spironolactone & {$[61-63]$} \\
\hline & Peroral antidiabetic drugs & Glitazones-pioglitazone & {$[64-66]$} \\
\hline & AGE cross-links breakers & Aminoguanidine & {$[67-70]$} \\
\hline \multirow{7}{*}{ Prevailing effect } & \multirow{2}{*}{ Antihypertensive } & Direct renin inhibitors & {$[39,71-73]$} \\
\hline & & Beta-blockers & {$[27,39,53,54,74-78]$} \\
\hline & Lipid lowering drugs & Statins & {$[79-87]$} \\
\hline & Peroral antidiabetic drugs & Metformin & {$[88,89]$} \\
\hline & AGE cross-links breakers & Alagebrium chloride & {$[16,90-92]$} \\
\hline & Anti-inflammatory drugs & Corticosteroids & {$[93]$} \\
\hline & $\begin{array}{l}\text { Endothelin-A receptor } \\
\text { antagonists }\end{array}$ & Sitaxsentan, BQ-123 & {$[94,95]$} \\
\hline \multirow{5}{*}{ Conflicting effect } & \multirow{2}{*}{ Antihypertensive } & Nitrates & {$[96]$} \\
\hline & & Aldosterone antagonists-eplerenone & {$[97-99]$} \\
\hline & Peroral antidiabetic drugs & Glitazones-rosiglitazone & {$[100-103]$} \\
\hline & \multirow[t]{2}{*}{ Anti-inflammatory drugs } & $\begin{array}{l}\text { Antibodies against tumor necrosis factor } \\
\text { alpha (anti-TNF- } \alpha)\end{array}$ & {$[104-110]$} \\
\hline & & Acetylsalicylic acid & {$[111,112]$} \\
\hline \multirow[t]{2}{*}{ Neutral effect } & Antihypertensive & Diuretics & $\begin{array}{l}{[34,37,46,55,59,61,113,} \\
114]\end{array}$ \\
\hline & Vasopeptidase inhibitors & Omapatrilat & {$[115,116]$} \\
\hline
\end{tabular}

[52], were proven to reduce central blood pressure more than the systolic blood pressure and increase pulse pressure, while reducing Aix and PWV. In addition, when ACE inhibitor and sartan were combined, they proved to achieve even greater effect on PWV reduction in patients with chronic kidney disease [38].

4.1.3. Beta-Blockers. Beta-blockers without vasodilating properties have been shown to have a weaker effect on arterial stiffness and central pulsatile hemodynamics than vasodilating drugs of other groups. Nevertheless, they showed the same extent of reduction of arterial stiffness per se as the other mentioned drugs. The mechanism of action is through heart rate reduction, as this influences the viscoelastic properties of the arterial wall. Reduced heart rate also leads to increased wave reflections, a lower reduction in aortic than brachial systolic blood pressure, and reduced pulse pressure amplification. Peripheral vasoconstriction, achieved by, for example, atenolol, is an additional mechanism responsible for the negative effect on wave reflections [74-77]. The REASON study evaluated the effect of atenolol on pulsatile hemodynamics. In this particular study central PP slightly increased, while peripheral PP drastically decreased. Also PWV decreased substantially, while Aix increased to a substantial degree.
These effects were attributed to the heart rate reduction [27]. Different studies are consistent, showing that atenolol negatively affects both pulse and systolic blood pressure (by increasing them) and wave reflections, increasing Aix, but, on the other hand, reducing aortic stiffness [53]. Thus the CAFÉ (Conduit Artery Functional Evaluation) study showed the superiority of amlodipine in this regard, leading to challenging the recommendation for the use of classical betablockers in hypertension treatment [32]. New, increasingly prescribed agents such as nebivolol and carvedilol, that also have vasodilating properties, seem to be more effective in improving central pulsatility. These effects appear to be related to their ability to donate NO, which dilates the small resistance arteries. The effects observed lead to pulse pressure amplification, but Aix reduction [39, 74-77].

4.1.4. Calcium Channel Blockers. Calcium channel blockers also lower PWV and reduce wave reflections, but to a lesser degree than renin-angiotensin inhibitors. The largest amount of evidence is for the dihydropyridine calcium channel blocker amlodipine [32, 34, 37, 46, 49, 55]. This drug was evaluated in the CAFÉ study, among other trials, where it proved to reduce central blood pressure more than peripheral blood pressure; it amplified pulse pressure and reduced Aix 
and PWV, thus displaying its destiffening effect [32]. Similar results were obtained for the other calcium channel blockers that were evaluated, namely, azelnidipine [56], barnidipine [57], nitrendipine [58], felodipine [55], lercanidipine [59], and verapamil [60].

4.1.5. Diuretics. Diuretics seem to have no beneficial effect on pulsatile hemodynamics. Many agents were studied, including hydrochlorothiazide, which showed a neutral effect on reduction of central blood pressure and a neutral effect on pulse pressure amplification $[37,55]$. Consistent data is available for bendrofluazide $[34,59,61,113]$ and indapamide $[37,46,113,114]$, which also have a neutral effect on Aix and PWV, respectively.

4.1.6. Aldosterone Antagonists. The aldosterone antagonist spironolactone proved to reduce PWV and Aix when adjusted for blood pressure, compared to bendrofluazide [61]. The beneficial effect of spironolactone in this regard was also obtained in early stage chronic kidney disease and in patients with nonischemic dilated cardiomyopathy [62, 63]. Similar results were obtained for eplerenone when compared to amlodipine, but its effect proved to be much greater in reducing vascular stiffness and the collagen-elastin ratio when compared to atenolol $[97,98]$. These effects were not observed in chronic kidney disease patients stages 3 and 4 [99].

4.1.7. Direct Renin Inhibitors. Direct renin inhibitor, that is, aliskiren, the only one available, was evaluated in diabetes mellitus type 1 and type 2 patients where it reduced PWV as well as Aix, thus showing a beneficial destiffening effect $[39,71,72]$. On the other hand, in patients with essential hypertension, it reduced PWV without influencing Aix [73].

4.1.8. Nitrates. Nitrates have also been studied in this regard. As vasodilating drugs, they influence the smooth muscle cells of large arteries, leading to possible arterial destiffening. Their effect was evaluated in hypertensive patients, where isosorbide mononitrate proved to amplify systolic and pulse pressure but substantially reduced Aix. On the other hand, they did not influence PWV, therefore leading to the conclusion that their effect on arterial stiffness was minimal [96].

It seems that arterial stiffness reduction can be obtained with different antihypertensive drugs. The highest effects are exerted by inhibitors of the renin-angiotensin system. Stiffness reduction seems to be correlated with the dose of antihypertensive drug. Long-term treatment also seems to have a greater effect. Mechanisms behind this are the slow extracellular matrix turnover, the long-term constant of arterial remodeling, and the necessity that the target tissue systems influence changes in arterial stiffness more than blood pressure [117].

4.2. Statins. Statins (HMG-CoA reductase inhibitors), besides their basic action in reducing low-density lipoprotein (LDL) cholesterol, also have several additional protective/ beneficial effects (pleiotropic effects) on the cardiovascular system [79]. There are conflicting reports in the literature on whether statins could improve arterial stiffness directly. Rizos et al. reviewed 9 randomized controlled studies (RCT) with 471 participants. In four of them central aortic PWV was assessed; fluvastatin decreased PWV in two studies, whereas in one study the change was not significant and in another study a significant increase in PWV was observed. In the other five studies peripheral (mainly brachial-ankle) PWV was assessed; fluvastatin decreased PWV in all except one study [80]. Arterial stiffness was improved with atorvastatin (40 mg daily) in patients with ischemic heart failure [81]. Low-dose atorvastatin (10 mg daily) was shown to improve arterial stiffness in a double blind, randomized, placebocontrolled study on hypertensive and hypercholesterolemic patients after 26 weeks of treatment [82]. Similarly, it also prevented an increase in arterial stiffness in patients with chronic kidney disease [83]. Statin treatment significantly improved arterial stiffness through decrease of PWV in normotensive patients with coronary artery disease (CAD), but not in hypertensive patients with CAD [84]. The possible mechanisms behind these observed phenomena are that statins act in an anti-inflammatory and antioxidative manner in the arterial wall, which was shown only in relatively small studies [85-87].

4.3. Peroral Antidiabetic Drugs. Treatment with glitazones, peroxisome proliferator-activated receptor gamma (PPAR- $\gamma$ ) agonists, was shown not only to improve insulin resistance and glycemic control, but also to decrease arterial stiffness in patients with type 2 diabetes mellitus [64, 100, 101]. PPAR receptors were also proven to be expressed in the vascular tissue and influence vascular homeostasis [118]. In the literature it was shown that pioglitazone decreased arterial stiffness in patients with diabetes mellitus type 2 [64] and in obese glucose tolerant men [65]. For rosiglitazone there are conflicting results; in some studies it decreased PWV, which was associated with anti-inflammatory action [100-102]. In another study, eight-week treatment with rosiglitazone failed to improve arterial stiffness in patients with chronic kidney disease, but the study was small (70 patients, divided equally among treatment and placebo groups) [103]. Treatment with pioglitazone and rosiglitazone was associated with improvement in adiponectin levels [66]. Besides glitazones, metformin was also shown to reduce arterial stiffness in several studies, including women with polycystic ovary syndrome $[88,89]$.

4.4. AGE Cross-Link Breakers. Cross-links between collagen and elastin in the vascular wall are important in providing strength and elasticity to the vessels. Due to nonenzymatic glycation of proteins, especially collagen, AGE are formed, which accumulate and increase collagen cross-linking and consequently progressively increase arterial stiffness. Formation of AGE occurs with aging and is accelerated in diabetes mellitus and hypertension [119]. Newer therapeutics are directed at the cross-linking of collagen, a process previously thought to be irreversible. They can either block the formation of AGE (aminoguanidine) or nonenzymatically break 
AGE cross-links (alagebrium chloride) and could potentially decrease arterial stiffness [120]. Aminoguanidine was tested mainly in animal studies, where it decreased arterial stiffness parameters [67-69], and only in one human study [70]. Alagebrium chloride (ALT-711) was shown to decrease arterial stiffness in several animal and human studies [16, 90, 91], but not in all [92]. Drugs that block the receptor for AGE (RAGE), or serve as a sham RAGE, are under development [120].

4.5. Anti-Inflammatory Drugs. Inflammation states, such as inflammatory bowel disease $[121,122]$, rheumatoid arthritis, and low-grade systemic inflammation with increased Creactive protein [123], are associated with the arterial stiffening process. Several anti-inflammatory drugs tested were shown to reduce arterial stiffness [124]. Antibodies against tumor necrosis factor alpha (anti-TNF- $\alpha$ ) were shown to be effective in improving arterial stiffness in several studies, including patients with chronic inflammatory diseases [104107]. In contrast, in recent studies they failed to influence arterial stiffness [108-110]. Corticosteroids could also improve arterial stiffness [93]. Conflicting results were also published for acetylsalicylic acid (Aspirin), which could potentially improve arterial stiffness due to its anti-inflammatory effect $[111,112]$.

4.6. Endothelin-A Receptor Antagonists. The serum concentration of endothelin-1 was shown to correlate with aortic elasticity parameters in 152 subjects with essential hypertension [125]. Therefore, selective endothelin-A receptor antagonists could improve arterial stiffness. The beneficial effect of selective endothelin-A receptor antagonists (sitaxsentan, BQ-123) in improving arterial stiffness was shown in studies including patients with chronic kidney disease [94, 95]. Obviously large clinical studies are needed to definitely prove this effect.

4.7. Vasopeptidase Inhibitors. Vasopeptidase inhibitors are a new class of drugs that act on two key enzymes in the metabolism of vasoactive peptides: they inhibit ACE to reduce vasoconstriction and inhibit endopeptidase, which is involved in the degradation of several natriuretic peptides, to enhance vasodilation $[126,127]$. In a study performed on 167 patients the vasopeptidase inhibitor omapatrilat reduced Aix but failed to influence arterial stiffness [115]. Vascular stiffness was also unaltered by omapatrilat in a study on stroke-prone spontaneously hypertensive rats [116]. Therefore, further studies are needed to investigate the influence of vasopeptidase inhibitors on arterial stiffness.

\section{Emerging Pharmacological Approaches}

New, innovative therapeutic pharmacological options are emerging and show some promise [128]. Short term, low-dose treatment with a statin and sartan separately, but particularly their combination, was shown to improve endothelial function and arterial stiffness parameters in apparently healthy participants, as well as in patients with diabetes mellitus type
1 [129-132]. This approach is oriented directly to arterial function improvement and represents a simple preventive approach against arterial aging.

\section{Conclusion}

Arterial stiffness progressively increases with age and was found to be a risk factor of cardiovascular disease. Therefore, besides identifying solely classical cardiovascular risk factors, it appears to be more and more important to assess arterial stiffness, which could be easily measured noninvasively and expressed as PWV. This modified or advanced approach enables better cardiovascular risk stratification. We believe that such an approach should be introduced into the treatment and prevention of cardiovascular disease. At the present there are several pharmacological agents which could influence arterial stiffness. Consequently, the present review focused on a survey of different pharmacological therapeutic options for decreasing arterial stiffness. However, new and more effective treatment is highly desirable. Furthermore, future studies should address the influence of decrease in arterial stiffness on major adverse cardiovascular and cerebrovascular events (MACCE).

\section{Conflict of Interests}

The authors declare that there is no conflict of interests regarding the publication of this paper.

\section{References}

[1] K. Christensen, G. Doblhammer, R. Rau, and J. W. Vaupel, "Ageing populations: the challenges ahead," The Lancet, vol. 374, no. 9696, pp. 1196-1208, 2009.

[2] W. Lutz, W. Sanderson, and S. Scherbov, "The coming acceleration of global population ageing," Nature, vol. 451, no. 7179, pp. 716-719, 2008.

[3] M. D. Cheitlin, "Cardiovascular physiology_changes with aging," The American Journal of Geriatric Cardiology, vol. 12, no. 1, pp. 9-13, 2003.

[4] J. L. Fleg and J. Strait, "Age-associated changes in cardiovascular structure and function: a fertile milieu for future disease," Heart Failure Reviews, vol. 17, no. 4-5, pp. 545-554, 2012.

[5] H. Tomiyama and A. Yamashina, "Non-invasive vascular function tests: their pathophysiological background and clinical application," Circulation Journal, vol. 74, no. 1, pp. 24-33, 2010.

[6] S. Sethi, O. Rivera, R. Oliveros, and R. Chilton, "Aortic stiffness: pathophysiology, clinical implications, and approach to treatment," Journal of Integrated Blood Pressure Control, vol. 7, pp. 29-34, 2014.

[7] A. L. Wentland, T. M. Grist, and O. Wieben, "Review of MRIbased measurements of pulse wave velocity: a biomarker of arterial stiffness," Cardiovascular Diagnosis and Therapy, vol. 4, no. 2, pp. 193-206, 2014.

[8] Y. Ben-Shlomo, M. Spears, C. Boustred et al., "Aortic pulse wave velocity improves cardiovascular event prediction: an individual participant meta-analysis of prospective observational data from 17,635 subjects," Journal of the American College of Cardiology, vol. 63, no. 7, pp. 636-646, 2014. 
[9] G. M. London and J. N. Cohn, "Prognostic application of arterial stiffness: task forces," The American Journal of Hypertension, vol. 15, no. 8, pp. 754-758, 2002.

[10] J. E. Wagenseil and R. P. Mecham, "Vascular extracellular matrix and arterial mechanics," Physiological Reviews, vol. 89, no. 3, pp. 957-989, 2009.

[11] A. P. Avolio, L. M. van Bortel, P. Boutouyrie et al., "Role of pulse pressure amplification in arterial hypertension: experts' opinion and review of the data," Hypertension, vol. 54, no. 2, pp. 375-383, 2009.

[12] C. Vlachopoulos, K. Aznaouridis, and C. Stefanadis, "Prediction of cardiovascular events and all-cause mortality with arterial stiffness: a systematic review and meta-analysis," Journal of the American College of Cardiology, vol. 55, no. 13, pp. 1318$1327,2010$.

[13] S. E. Greenwald, J. E. Moore Jr., A. Rachev, T. P. C. Kane, and J. J. Meister, "Experimental investigation of the distribution of residual strains in the artery wall," Journal of Biomechanical Engineering, vol. 119, no. 4, pp. 438-444, 1997.

[14] S. A. Hope and A. D. Hughes, "Drug effects on the mechanical properties of large arteries in humans," Clinical and Experimental Pharmacology and Physiology, vol. 34, no. 7, pp. 688-693, 2007.

[15] S. Laurent, P. Boutouyrie, and P. Lacolley, "Structural and genetic bases of arterial stiffness," Hypertension, vol. 45, no. 6, pp. 1050-1055, 2005.

[16] P. V. Vaitkevicius, M. Lane, H. Spurgeon et al., "A crosslink breaker has sustained effects on arterial and ventricular properties in older rhesus monkeys," Proceedings of the National Academy of Sciences of the United States of America, vol. 98, no. 3, pp. 1171-1175, 2001.

[17] A. Tsamis, J. T. Krawiec, and D. A. Vorp, "Elastin and collagen fibre microstructure of the human aorta in ageing and disease: a review," Journal of the Royal Society Interface, vol. 10, no. 83, Article ID 20121004, 2013.

[18] R. P. Vito and S. A. Dixon, "Blood vessel constitutive models1995-2002," Annual Review of Biomedical Engineering, vol. 5, pp. 413-439, 2003.

[19] P. K. Hamilton, C. J. Lockhart, C. E. Quinn, and G. E. McVeigh, "Arterial stiffness: clinical relevance, measurement and treatment," Clinical Science, vol. 113, no. 3-4, pp. 157-170, 2007.

[20] G. F. Mitchell, "Effects of central arterial aging on the structure and function of the peripheral vasculature: implications for end-organ damage," Journal of Applied Physiology, vol. 105, no. 5, pp. 1652-1660, 2008.

[21] S. Kinlay, M. A. Creager, M. Fukumoto et al., "Endotheliumderived nitric oxide regulates arterial elasticity in human arteries in vivo," Hypertension, vol. 38, no. 5, pp. 1049-1053, 2001.

[22] O. Mirea, I. Donoiu, and I. E. Pleşea, "Arterial aging: a brief review," Romanian Journal of Morphology and Embryology, vol. 53, no. 3, pp. 473-477, 2012.

[23] M. M. Polovina and T. S. Potpara, "Endothelial dysfunction in metabolic and vascular disorders," Postgraduate Medicine, vol. 126, no. 2, pp. 38-53, 2014.

[24] A. Mahmud and J. Feely, "Arterial stiffness and the renin-angiotensin-aldosterone system," Journal of the Renin-AngiotensinAldosterone System, vol. 5, no. 3, pp. 102-108, 2004.

[25] Y. Shahin, J. A. Khan, and I. Chetter, "Angiotensin converting enzyme inhibitors effect on arterial stiffness and wave reflections: a meta-analysis and meta-regression of randomised controlled trials," Atherosclerosis, vol. 221, no. 1, pp. 18-33, 2012.

[26] N. de Luca, R. G. Asmar, G. M. London, M. F. O'Rourke, and M. E. Safar, "Selective reduction of cardiac mass and central blood pressure on low-dose combination perindopril/indapamide in hypertensive subjects," Journal of Hypertension, vol. 22, no. 8, pp. 1623-1630, 2004.

[27] G. M. London, R. G. Asmar, M. F. O’Rourke, and M. E. Safar, "Mechanism(s) of selective systolic blood pressure reduction after a low-dose combination of perindopril/indapamide in hypertensive subjects: comparison with atenolol," Journal of the American College of Cardiology, vol. 43, no. 1, pp. 92-99, 2004.

[28] A. Kengne, S. Czernichow, R. Huxley et al., "Blood pressure variables and cardiovascular risk: new findings from ADVANCE," Hypertension, vol. 54, no. 2, pp. 399-404, 2009.

[29] G. F. Mitchell, M. E. Dunlap, W. Warnica et al., "Longterm trandolapril treatment is associated with reduced aortic stiffness: the prevention of events with angiotensin-converting enzyme inhibition hemodynamic substudy," Hypertension, vol. 49, no. 6, pp. 1271-1277, 2007.

[30] A. D. Protogerou, G. S. Stergiou, C. Vlachopoulos, J. Blacher, and A. Achimastos, "The effect of antihypertensive drugs on central blood pressure beyond peripheral blood pressure. Part II: evidence for specific class-effects of antihypertensive drugs on pressure amplification," Current Pharmaceutical Design, vol. 15, no. 3, pp. 272-289, 2009.

[31] K. A. Aznaouridis, K. S. Stamatelopoulos, E. N. Karatzis, A. D. Protogerou, C. M. Papamichael, and J. P. Lekakis, "Acute effects of renin-angiotensin system blockade on arterial function in hypertensive patients," Journal of Human Hypertension, vol. 21, no. 8, pp. 654-663, 2007.

[32] B. Williams, P. S. Lacy, S. M. Thom et al., "Differential impact of blood pressure-lowering drugs on central aortic pressure and clinical outcomes: principal results of the Conduit Artery Function Evaluation (CAFE) study," Circulation, vol. 113, no. 9, pp. 1213-1225, 2006.

[33] T. Kaiser, T. Heise, L. Nosek, U. Eckers, and P. T. Sawicki, "Influence of nebivolol and enalapril on metabolic parameters and arterial stiffness in hypertensive type 2 diabetic patients," Journal of Hypertension, vol. 24, no. 7, pp. 1397-1403, 2006.

[34] A. J. Deary, A. L. Schumann, H. Murfet, S. Haydock, R. S. Foo, and M. J. Brown, "Influence of drugs and gender on the arterial pulse wave and natriuretic peptide secretion in untreated patients with essential hypertension," Clinical Science, vol. 103, no. 5, pp. 493-499, 2002.

[35] K. Hirata, C. Vlachopoulos, A. Adji, and M. F. O’Rourke, "Benefits from angiotensin-converting enzyme inhibitor "beyond blood pressure lowering": beyond blood pressure or beyond the brachial artery?" Journal of Hypertension, vol. 23, no. 3, pp. 551556, 2005.

[36] G. M. London, B. Pannier, E. Vicaut et al., "Antihypertensive effects and arterial haemodynamic alterations during angiotensin converting enzyme inhibition," Journal of Hypertension, vol. 14, no. 9, pp. 1139-1146, 1996.

[37] J. M. Ferguson, J. Minas, S. Siapantas, P. A. Komesaroff, and K. Sudhir, "Effects of a fixed-dose ACE inhibitor-diuretic combination on ambulatory blood pressure and arterial properties in isolated systolic hypertension," Journal of Cardiovascular Pharmacology, vol. 51, no. 6, pp. 590-595, 2008.

[38] M. Frimodt-Møller, A. L. Kamper, S. Strandgaard, S. Kreiner, and A. H. Nielsen, "Beneficial effects on arterial stiffness and pulse-wave reflection of combined enalapril and candesartan in 
chronic kidney disease-a randomized trial," PLoS ONE, vol. 7, no. 7, Article ID e41757, 2012.

[39] C. Koumaras, K. Tziomalos, E. Stavrinou et al., "Effects of reninangiotensin-aldosterone system inhibitors and beta-blockers on markers of arterial stiffness," Journal of the American Society of Hypertension, vol. 8, no. 2, pp. 74-82, 2014.

[40] S. V. Nedogoda, A. A. Ledyaeva, E. V. Chumachok et al., "Randomized trial of perindopril, enalapril, losartan and telmisartan in overweight or obese patients with hypertension," Clinical Drug Investigation, vol. 33, no. 8, pp. 553-561, 2013.

[41] A. Mahmud and J. Feely, "Favourable effects on arterial wave reflection and pulse pressure amplification of adding angiotensin II receptor blockade in resistant hypertension," Journal of Human Hypertension, vol. 14, no. 9, pp. 541-546, 2000.

[42] A. Mahmud and J. Feely, "Reduction in arterial stiffness with angiotensin II antagonist is comparable with and additive to ACE inhibition," The American Journal of Hypertension, vol. 15, no. 4 I, pp. 321-325, 2002.

[43] B. Dahlöf, R. B. Devereux, S. E. Kjeldsen et al., "Cardiovascular morbidity and mortality in the Losartan Intervention For Endpoint reduction in hypertension study (LIFE): a randomised trial against atenolol," The Lancet, vol. 359, no. 9311, pp. 9951003, 2002.

[44] K. Dickstein, J. Kjekshus, and O. S. C. o. t. O. S. Group, "Effects of losartan and captopril on mortality and morbidity in highrisk patients after acute myocardial infarction: the OPTIMAAL randomised trial. Optimal Trial in Myocardial Infarction with Angiotensin II Antagonist Losartan," The Lancet, vol. 360, pp. 752-760, 2002.

[45] L. Ghiadoni, A. Virdis, A. Magagna, S. Taddei, and A. Salvetti, "Effect of the angiotensin II type 1 receptor blocker candesartan on endothelial function in patients with essential hypertension," Hypertension, vol. 35, no. 1, pp. 501-506, 2000.

[46] D. Agnoletti, Y. Zhang, C. Borghi, J. Blacher, and M. E. Safar, "Effects of antihypertensive drugs on central blood pressure in humans: a preliminary observation," The American Journal of Hypertension, vol. 26, no. 8, pp. 1045-1052, 2013.

[47] S. Julius, S. E. Kjeldsen, M. Weber et al., "Outcomes in hypertensive patients at high cardiovascular risk treated with regimens based on valsartan or amlodipine: the VALUE randomised trial," The Lancet, vol. 363, no. 9426, pp. 2022-2031, 2004.

[48] S. Julius, M. A. Weber, S. E. Kjeldsen et al., "The Valsartan Antihypertensive Long-Term Use Evaluation (VALUE) trial: outcomes in patients receiving monotherapy," Hypertension, vol. 48, no. 3, pp. 385-391, 2006.

[49] D. Hayoz, D. H. Zappe, M. A. R. Meyer et al., "Changes in aortic pulse wave velocity in hypertensive postmenopausal women: comparison between a calcium channel blocker vs angiotensin receptor blocker regimen," Journal of Clinical Hypertension, vol. 14, no. 11, pp. 773-778, 2012.

[50] J. D. Mediavilla Garcia, C. Fernandez-Torres, F. Jaen Aguila, and J. Jimenez-Alonso, "Effect of olmesartan medoxomil on arterial stiffness in patients with essential hypertension," Medicina Clínica, vol. 128, no. 19, pp. 726-729, 2007.

[51] R. Asmar, "Effect of telmisartan on arterial distensibility and central blood pressure in patients with mild to moderate hypertension and Type 2 diabetes mellitus," Journal of the ReninAngiotensin-Aldosterone System, vol. 2, no. 2, pp. S8-S11, 2001.

[52] Z. Dhakam, C. M. McEniery, J. R. Cockcroft, M. J. Brown, and I. B. Wilkinson, "Atenolol and eprosartan: differential effects on central blood pressure and aortic pulse wave velocity," The
American Journal of Hypertension, vol. 19, no. 2, pp. 214-219, 2006.

[53] A. Jekell, K. Malmqvist, N. H. Wallen, D. Mortsell, and T. Kahan, "Markers of inflammation, endothelial activation, and arterial stiffness in hypertensive heart disease and the effects of treatment: results from the SILVHIA study," Journal of Cardiovascular Pharmacology, vol. 62, no. 6, pp. 559-566, 2013.

[54] C. Vitale, G. Marazzi, F. Iellamo et al., "Effects of nebivolol or irbesartan in combination with hydrochlorothiazide on vascular functions in newly-diagnosed hypertensive patients: the NINFE (Nebivololo, Irbesartan Nella Funzione Endoteliale) study," International Journal of Cardiology, vol. 155, no. 2, pp. 279-284, 2012.

[55] T. Morgan, J. Lauri, D. Bertram, and A. Anderson, "Effect of different antihypertensive drug classes on central aortic pressure," The American Journal of Hypertension, vol. 17, no. 2, pp. 118-123, 2004.

[56] Y. Matsui, K. Eguchi, M. F. O’Rourke et al., "Differential effects between a calcium channel blocker and a diuretic when used in combination with angiotensin II receptor blocker on central aortic pressure in hypertensive patients," Hypertension, vol. 54, no. 4, pp. 716-723, 2009.

[57] C. Palombo, E. Malshi, C. Morizzo et al., "Arterial wave reflection during antihypertensive therapy with barnidipine: a 6-month, open-label study using an integrated cardiovascular ultrasound approach in patients with newly diagnosed hypertension," Clinical Therapeutics, vol. 31, no. 12, pp. 2873-2885, 2009.

[58] G. M. London, B. Pannier, A. P. Guerin, S. J. Marchais, M. E. Safar, and J. Cuche, "Cardiac hypertrophy, aortic compliance, peripheral resistance, and wave reflection in end-stage renal disease: comparative effects of ACE inhibition and calcium channel blockade," Circulation, vol. 90, no. 6, pp. 2786-2796, 1994.

[59] I. S. MacKenzie, C. M. McEniery, Z. Dhakam, M. J. Brown, J. R. Cockcroft, and I. B. Wilkinson, "Comparison of the effects of antihypertensive agents on central blood pressure and arterial stiffness in isolated systolic hypertension," Hypertension, vol. 54, no. 2, pp. 409-413, 2009.

[60] J. Topouchian, R. Asmar, F. Sayegh et al., "Changes in arterial structure and function under trandolapril-verapamil combination in hypertension," Stroke, vol. 30, no. 5, pp. 1056-1064, 1999.

[61] A. Mahmud and J. Feely, "Aldosterone-to-renin ratio, arterial stiffness, and the response to aldosterone antagonism in essential hypertension," American Journal of Hypertension, vol. 18, no. 1, pp. 50-55, 2005.

[62] N. C. Edwards, R. P. Steeds, P. M. Stewart, C. J. Ferro, and J. N. Townend, "Effect of spironolactone on left ventricular mass and aortic stiffness in early-stage chronic kidney disease: a randomized controlled trial," Journal of the American College of Cardiology, vol. 54, no. 6, pp. 505-512, 2009.

[63] E. Vizzardi, P. D. Pina, G. Caretta et al., "The effect of aldosterone-antagonist therapy on aortic elastic properties in patients with nonischemic dilated cardiomyopathy," Journal of Cardiovascular Medicine. In press.

[64] K. Harashima, J. Hayashi, T. Miwa, and T. Tsunoda, "Long-term pioglitazone therapy improves arterial stiffness in patients with type 2 diabetes mellitus," Metabolism, vol. 58, no. 6, pp. 739-745, 2009.

[65] K. E. Ryan, D. R. McCance, L. Powell, R. McMahon, and E. R. Trimble, "Fenofibrate and pioglitazone improve endothelial 
function and reduce arterial stiffness in obese glucose tolerant men," Atherosclerosis, vol. 194, no. 2, pp. el23-e130, 2007.

[66] O. Oz, E. Tuncel, S. Eryilmaz et al., "Arterial elasticity and plasma levels of adiponectin and leptin in type 2 diabetic patients treated with thiazolidinediones," Endocrine, vol. 33, no. 1, pp. 101-105, 2008.

[67] C. Cantini, P. Kieffer, B. Corman, P. Limiñana, J. Atkinson, and I. Lartaud-Idjouadiene, "Aminoguanidine and aortic wall mechanics, structure, and composition in aged rats," Hypertension, vol. 38, no. 4, pp. 943-948, 2001.

[68] K. Chang, K. Hsu, C. Tseng, Y. Lin, Y. Cho, and Y. Tseng, "Aminoguanidine prevents arterial stiffening and cardiac hypertrophy in streptozotocin-induced diabetes in rats," British Journal of Pharmacology, vol. 147, no. 8, pp. 944-950, 2006.

[69] K. C. Chang, C. D. Tseng, M. S. Wu et al., "Aminoguanidine prevents arterial stiffening in a new rat model of type 2 diabetes," European Journal of Clinical Investigation, vol. 36, no. 8, pp. 528535, 2006.

[70] B. Corman, M. Duriez, P. Poitevin et al., "Aminoguanidine prevents age-related arterial stiffening and cardiac hypertrophy," Proceedings of the National Academy of Sciences of the United States of America, vol. 95, no. 3, pp. 1301-1306, 1998.

[71] D. Z. I. Cherney, V. Lai, J. W. Scholey, J. A. Miller, B. Zinman, and H. N. Reich, "Effect of direct renin inhibition on renal hemodynamic function, arterial stiffness, and endothelial function in humans with uncomplicated type 1 diabetes: a pilot study," Diabetes Care, vol. 33, no. 2, pp. 361-365, 2010.

[72] A. E. Raptis, K. P. Markakis, M. C. Mazioti et al., "Effect of aliskiren on circulating endothelial progenitor cells and vascular function in patients with type 2 diabetes and essential hypertension," American Journal of Hypertension, 2014.

[73] I. Bonadei, E. Vizzardi, A. D’Aloia, E. Sciatti, R. Raddino, and M. Metra, "Role of aliskiren on arterial stiffness and endothelial function in patients with primary hypertension," Journal of Clinical Hypertension, vol. 16, no. 3, pp. 202-206, 2014.

[74] E. Agabiti-Rosei, E. Porteri, and D. Rizzoni, "Arterial stiffness, hypertension, and rational use of nebivolol," Vascular Health and Risk Management, vol. 5, no. 1, pp. 353-360, 2009.

[75] A. Mahmud and J. Feely, “ $\beta$-blockers reduce aortic stiffness in hypertension but nebivolol, not atenolol, reduces wave reflection," American Journal of Hypertension, vol. 21, no. 6, pp. 663-667, 2008.

[76] C. M. McEniery, M. Schmitt, A. Qasem et al., "Nebivolol increases arterial distensibility in vivo," Hypertension, vol. 44, no. 3, pp. 305-310, 2004.

[77] J. Polónia, L. Barbosa, J. A. Silva, and S. Bertoquini, “Different patterns of peripheral versus central blood pressure in hypertensive patients treated with $\beta$-blockers either with or without vasodilator properties or with angiotensin receptor blockers," Blood Pressure Monitoring, vol. 15, no. 5, pp. 235-239, 2010.

[78] F. H. Ding, Y. Li, L. H. Li, and J. G. Wang, "Impact of heart rate on central hemodynamics and stroke: $s$ meta-analysis of $\beta$ blocker trials," American Journal of Hypertension, vol. 26, no. 1, pp. 118-125, 2013.

[79] C. G. Mihos, A. M. Pineda, and O. Santana, "Cardiovascular effects of statins, beyond lipid-lowering properties," Pharmacological Research, 2014.

[80] E. C. Rizos, A. P. Agouridis, and M. S. Elisaf, "The effect of statin therapy on arterial stiffness by measuring pulse wave velocity: a systematic review," Current Vascular Pharmacology, vol. 8, no. 5, pp. 638-644, 2010.
[81] D. Tousoulis, E. Oikonomou, G. Siasos et al., "Dose-dependent effects of short term atorvastatin treatment on arterial wall properties and on indices of left ventricular remodeling in ischemic heart failure," Atherosclerosis, vol. 227, no. 2, pp. 367372, 2013.

[82] A. I. Kanaki, P. A. Sarafidis, P. I. Georgianos et al., "Effects of low-dose atorvastatin on arterial stiffness and central aortic pressure augmentation in patients with hypertension and hypercholesterolemia," American Journal of Hypertension, vol. 26, no. 5, pp. 608-616, 2013.

[83] R. G. Fassett, I. K. Robertson, M. J. Ball, D. P. Geraghty, J. E. Sharman, and J. S. Coombes, "Effects of atorvastatin on arterial stiffness in chronic kidney disease: a randomised controlled trial," Journal of Atherosclerosis and Thrombosis, vol. 17, no. 3, pp. 235-241, 2010.

[84] Z. G. Wang, B. Chen, N. Q. Lü, Y. M. Cheng, and A. M. Dang, "Relationships between use of statins and arterial stiffness in normotensive and hypertensive patients with coronary artery disease," Chinese Medical Journal, vol. 126, no. 16, pp. 3087-3092, 2013.

[85] T. Matsuo, K. Iwade, N. Hirata et al., "Improvement of arterial stiffness by the antioxidant and anti-inflammatory effects of short-term statin therapy in patients with hypercholesterolemia," Heart and Vessels, vol. 20, no. 1, pp. 8-12, 2005.

[86] M. Hongo, H. Tsutsui, E. Mawatari et al., "Fluvastatin improves arterial stiffness in patients with coronary artery disease and hyperlipidemia-a 5-year follow-up study," Circulation Journal, vol. 72, no. 5, pp. 722-728, 2008.

[87] J. Wang, J. Xu, C. Zhou et al., "Improvement of arterial stiffness by reducing oxidative stress damage in elderly hypertensive patients after 6 months of atorvastatin therapy," Journal of Clinical Hypertension, vol. 14, no. 4, pp. 245-249, 2012.

[88] N. Agarwal, S. P. L. Rice, H. Bolusani et al., "Metformin reduces arterial stiffness and improves endothelial function in young women with polycystic ovary syndrome: a randomized, placebo-controlled, crossover trial," Journal of Clinical Endocrinology and Metabolism, vol. 95, no. 2, pp. 722-730, 2010.

[89] M. G. Kaya, B. Calapkorur, Z. Karaca et al., "The effects of treatment with drospirenone/ethinyl oestradiol alone or in combination with metformin on elastic properties of aorta in women with polycystic ovary syndrome," Clinical Endocrinology, vol. 77, no. 6, pp. 885-892, 2012.

[90] D. A. Kass, E. P. Shapiro, M. Kawaguchi et al., "Improved arterial compliance by a novel advanced glycation end-product crosslink breaker," Circulation, vol. 104, no. 13, pp. 1464-1470, 2001.

[91] J. Steppan, H. Tran, A. M. Benjo et al., "Alagebrium in combination with exercise ameliorates age-associated ventricular and vascular stiffness," Experimental Gerontology, vol. 47, no. 8, pp. 565-572, 2012.

[92] M. H. Oudegeest-Sander, M. G. Olde Rikkert, P. Smits et al., "The effect of an advanced glycation end-product crosslink breaker and exercise training on vascular function in older individuals: a randomized factorial design trial," Experimental Gerontology, vol. 48, no. 12, pp. 1509-1517, 2013.

[93] G. Schillaci, E. Bartoloni, G. Pucci et al., "Aortic stiffness is increased in polymyalgia rheumatica and improves after steroid treatment," Annals of the Rheumatic Diseases, vol. 71, no. 7, pp. 1151-1156, 2012.

[94] N. Dhaun, I. M. MacIntyre, D. Kerr et al., "Selective endothelina receptor antagonism reduces proteinuria, blood pressure, 
and arterial stiffness in chronic proteinuric kidney disease," Hypertension, vol. 57, no. 4, pp. 772-779, 2011.

[95] N. Dhaun, I. M. MacIntyre, V. Melville et al., "Blood pressureindependent reduction in proteinuria and arterial stiffness after acute endothelin-a receptor antagonism in chronic kidney disease," Hypertension, vol. 54, no. 1, pp. 113-119, 2009.

[96] G. S. Stokes, E. S. Barin, and K. L. Gilfillan, "Effects of isosorbide mononitrate and AII inhibition on pulse wave reflection in hypertension," Hypertension, vol. 41, no. 2, pp. 297-301, 2003.

[97] C. Savoia, R. M. Touyz, F. Amiri, and E. L. Schiffrin, "Selective mineralocorticoid receptor blocker eplerenone reduces resistance artery stiffness in hypertensive patients," Hypertension, vol. 51, no. 2, pp. 432-439, 2008.

[98] W. B. White, D. Duprez, R. St. Hillaire et al., "Effects of the selective aldosterone blocker eplerenone versus the calcium antagonist amlodipine in systolic hypertension," Hypertension, vol. 41, no. 5, pp. 1021-1026, 2003.

[99] L. Boesby, T. Elung-Jensen, S. Strandgaard, and A. Kamper, "Eplerenone attenuates pulse wave reflection in chronic kidney disease stage 3-4-a randomized controlled study," PLOS ONE, vol. 8, no. 5, Article ID e64549, 2013.

[100] S. Kiyici, C. Ersoy, A. Kaderli et al., "Effect of rosiglitazone, metformin and medical nutrition treatment on arterial stiffness, serum MMP-9 and MCP-1 levels in drug naive type 2 diabetic patients," Diabetes Research and Clinical Practice, vol. 86, no. 1, pp. 44-50, 2009.

[101] J. Yu, N. Jin, G. Wang, F. Zhang, J. Mao, and X. Wang, "Peroxisome proliferator-activated receptor $\gamma$ agonist improves arterial stiffness in patients with type 2 diabetes mellitus and coronary artery disease," Metabolism, vol. 56, no. 10, pp. 13961401, 2007.

[102] S. G. Kim, O. H. Ryu, H. Y. Kim et al., "Effect of rosiglitazone on plasma adiponectin levels and arterial stiffness in subjects with prediabetes or non-diabetic metabolic syndrome," European Journal of Endocrinology, vol. 154, no. 3, pp. 433-440, 2006.

[103] D. T. Chan, G. F. Watts, A. B. Irish, and G. K. Dogra, "Rosiglitazone does not improve vascular function in subjects with chronic kidney disease," Nephrology Dialysis Transplantation, vol. 26, no. 11, pp. 3543-3549, 2011.

[104] K. Angel, S. A. Provan, M. K. Fagerhol, P. Mowinckel, T. K. Kvien, and D. Atar, "Effect of 1-year anti-TNF- $\alpha$ therapy on aortic stiffness, carotid atherosclerosis, and calprotectin in inflammatory arthropathies: a controlled study," American Journal of Hypertension, vol. 25, no. 6, pp. 644-650, 2012.

[105] K. Angel, S. A. Provan, H. L. Gulseth, P. Mowinckel, T. K. Kvien, and D. Atar, "Tumor necrosis factor- $\alpha$ antagonists improve aortic stiffness in patients with inflammatory arthropathies: a controlled study," Hypertension, vol. 55, no. 2, pp. 333-338, 2010.

[106] K. L. Moreau, K. D. Deane, A. L. Meditz, and W. M. Kohrt, "Tumor necrosis factor- $\alpha$ inhibition improves endothelial function and decreases arterial stiffness in estrogen-deficient postmenopausal women," Atherosclerosis, vol. 230, no. 2, pp. 390396, 2013.

[107] K. M. Mäki-Petäjä, F. C. Hall, A. D. Booth et al., "Rheumatoid arthritis is associated with increased aortic pulse-wave velocity, which is reduced by anti-tumor necrosis factor- $\alpha$ therapy," Circulation, vol. 114, no. 11, pp. 1185-1192, 2006.

[108] E. Capkin, M. Karkucak, A. Kiris et al., "Anti-tnf- $\alpha$ therapy may not improve arterial stiffness in patients with as: a 24-week follow-up," Rheumatology, vol. 51, no. 5, Article ID ker434, pp. 910-914, 2012.
[109] S. Mathieu, B. Pereira, M. Couderc, E. Rabois, J. Dubost, and M. Soubrier, "No significant changes in arterial stiffness in patients with ankylosing spondylitis after tumour necrosis factor alpha blockade treatment for 6 and 12 months," Rheumatology, vol. 52, no. 1, pp. 204-209, 2013.

[110] S. Mathieu, B. Pereira, J. Dubost, J. Lusson, and M. Soubrier, "No significant change in arterial stiffness in RA after 6 months and 1 year of rituximab treatment," Rheumatology, vol. 51, no. 6, Article ID kes006, pp. 1107-1111, 2012.

[111] A. D. Blann, N. Kuzniatsova, and G. Y. H. Lip, "Vascular and platelet responses to aspirin in patients with coronary artery disease," European Journal of Clinical Investigation, vol. 43, no. 1, pp. 91-99, 2013.

[112] C. Vlachopoulos, I. Dima, K. Aznaouridis et al., "Acute systemic inflammation increases arterial stiffness and decreases wave reflections in healthy individuals," Circulation, vol. 112, no. 14, pp. 2193-2200, 2005.

[113] M. Alem, P. Milia, S. Muir, K. Lees, and M. Walters, "Comparison of the effects of diuretics on blood pressure and arterial stiffness in patients with stroke," Journal of Stroke and Cerebrovascular Diseases, vol. 17, no. 6, pp. 373-377, 2008.

[114] X. J. Jiang, M. F. O'Rourke, Y. Q. Zhang, X. Y. He, and L. S. Liu, "Superior effect of an angiotensin-converting enzyme inhibitor over a diuretic for reducing aortic systolic pressure," Journal of Hypertension, vol. 25, no. 5, pp. 1095-1099, 2007.

[115] G. F. Mitchell, Y. Lacourcière, J. M. O. Arnold, M. E. Dunlap, P. R. Conlin, and J. L. Izzo Jr., "Changes in aortic stiffness and augmentation index after acute converting enzyme or vasopeptidase inhibition," Hypertension, vol. 46, no. 5, pp. 11111117, 2005.

[116] H. D. Intengan and E. L. Schiffrin, "Vasopeptidase inhibition has potent effects on blood pressure and resistance arteries in stroke-prone spontaneously hypertensive rats," Hypertension, vol. 35, no. 6, pp. 1221-1225, 2000.

[117] C. Koumaras, M. Tzimou, E. Stavrinou et al., "Role of antihypertensive drugs in arterial "de-stiffening" and central pulsatile hemodynamics," The American Journal of Cardiovascular Drugs, vol. 12, no. 3, pp. 143-156, 2012.

[118] A. Oyekan, "PPARs and their effects on the cardiovascular system," Clinical and Experimental Hypertension, vol. 33, no. 5, pp. 287-293, 2011.

[119] D. Susic, "Cross-link breakers as a new therapeutic approach to cardiovascular disease," Biochemical Society Transactions, vol. 35, part 5, pp. 853-856, 2007.

[120] A. Geronikaki, A. Gavalas, V. Dislian, and G. Giannoglou, "Inhibition of renin-angiotensin system and advanced glycation end products formation: A promising therapeutic approach targeting on cardiovascular diseases," Cardiovascular and Hematological Agents in Medicinal Chemistry, vol. 5, no. 4, pp. 249-264, 2007.

[121] L. Zanoli, S. Rastelli, G. Inserra et al., "Increased arterial stiffness in inflammatory bowel diseases is dependent upon inflammation and reduced by immunomodulatory drugs," Atherosclerosis, vol. 234, no. 2, pp. 346-351, 2014.

[122] R. A. Akdoğan, M. E. Durakoğlugil, S. A. Kocaman et al., "Increased pulse wave velocity and carotid intima-media thickness in patients with ulcerative colitis," Digestive Diseases and Sciences, vol. 58, no. 8, pp. 2293-2300, 2013.

[123] E. Gkaliagkousi, E. Gavriilaki, M. Doumas, K. Petidis, S. Aslanidis, and D. Stella, "Cardiovascular risk in rheumatoid arthritis: pathogenesis, diagnosis, and management," Journal of Clinical Rheumatology, vol. 18, no. 8, pp. 422-430, 2012. 
[124] K. M. Mäki-Petäjä and I. B. Wilkinson, "Anti-inflammatory drugs and statins for arterial stiffness reduction," Current Pharmaceutical Design, vol. 15, no. 3, pp. 290-303, 2009.

[125] G. Nar, K. Soylu, M. Akcay et al., "Evaluation of the relationship between arterial blood pressure, aortic stiffness and serum endothelin-1 levels in patients with essential hypertension," Clinical and Experimental Hypertension, vol. 35, no. 8, pp. 589594, 2013.

[126] T. Quaschning, F. Ruschitzka, and T. F. Lüscher, "Vasopeptidase inhibition: effective blood pressure control for vascular protection.", Current hypertension reports, vol. 4, no. 1, pp. 78-84, 2002.

[127] G. A. Sagnella, "Vasopeptidase inhibitors," Journal of the ReninAngiotensin-Aldosterone System, vol. 3, no. 2, pp. 90-95, 2002.

[128] M. Janić, M. Lunder, and M. Šabovič, "A new anti-ageing strategy focused on prevention of arterial ageing in the middleaged population," Medical Hypotheses, vol. 80, no. 6, pp. 837840, 2013.

[129] M. Lunder, M. Janić, S. Habjan, and M. Šabovič, "Subtherapeutic, low-dose fluvastatin improves functional and morphological arterial wall properties in apparently healthy, middle-aged males-a pilot study," Atherosclerosis, vol. 215, no. 2, pp. 446451, 2011.

[130] M. Lunder, M. Janić, and M. Šabovič, "Reduction of ageassociated arterial wall changes by low-dose valsartan," European Journal of Preventive Cardiology, vol. 19, no. 6, pp. 12431249, 2012.

[131] M. Lunder, M. Janić, B. Jug, and M. Šabovič, "The effects of low-dose fluvastatin and valsartan combination on arterial function: a randomized clinical trial," European Journal of Internal Medicine, vol. 23, no. 3, pp. 261-266, 2012.

[132] V. Savić, B. Eržen, M. Janić et al., "Improvement of arterial wall characteristics by the low-dose fluvastatin and valsartan combination in type 1 diabetes mellitus patients," Diabetes and Vascular Disease Research, vol. 10, no. 5, pp. 420-425, 2013. 


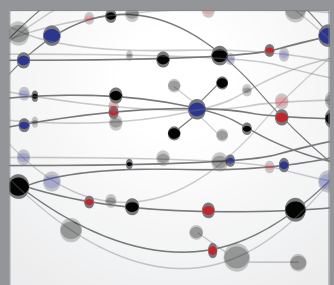

The Scientific World Journal
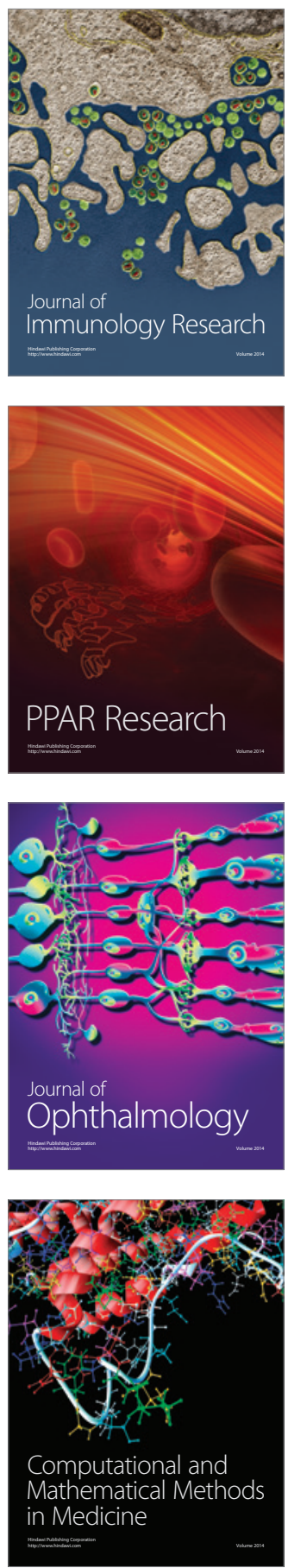

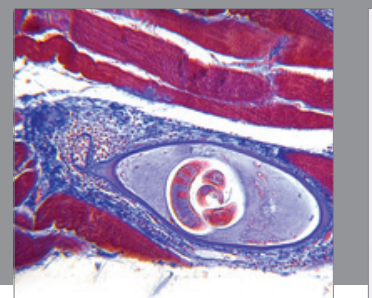

Gastroenterology

Research and Practice
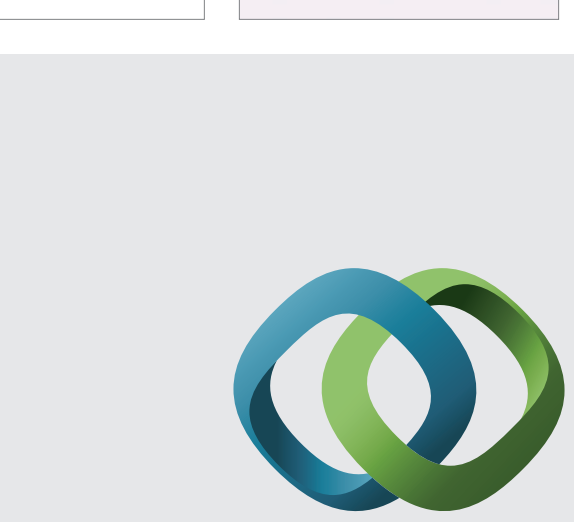

\section{Hindawi}

Submit your manuscripts at

http://www.hindawi.com
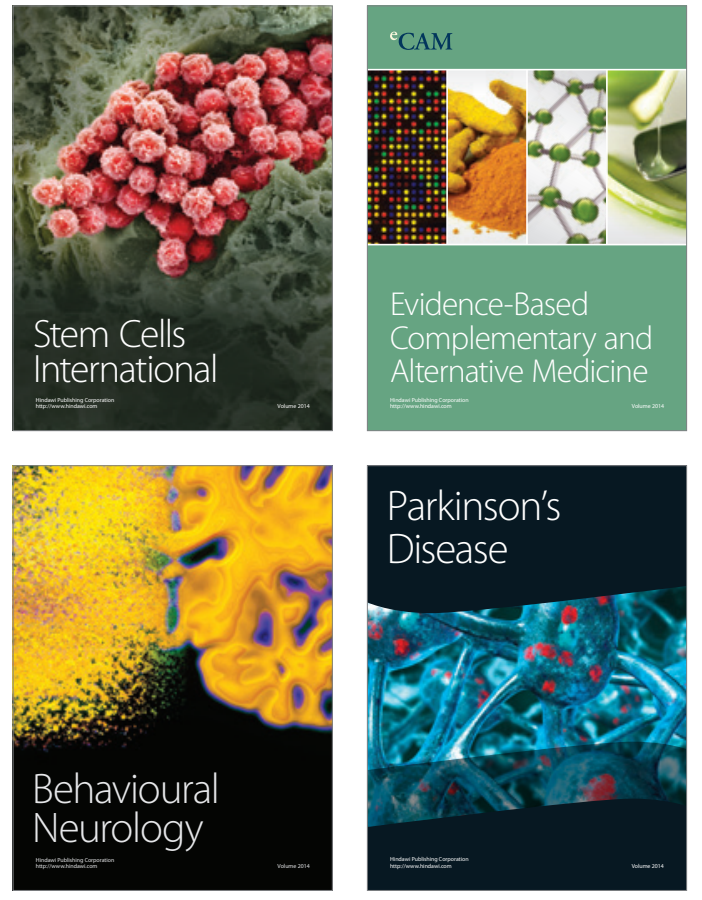
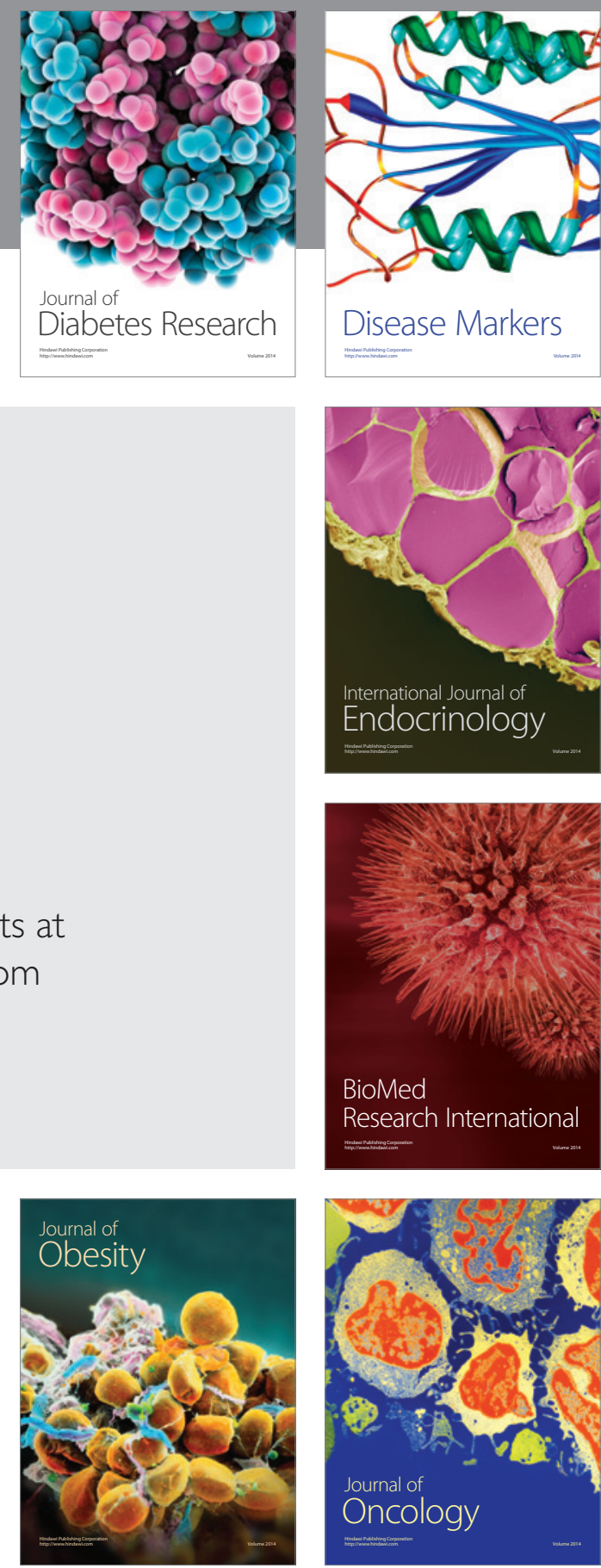

Disease Markers
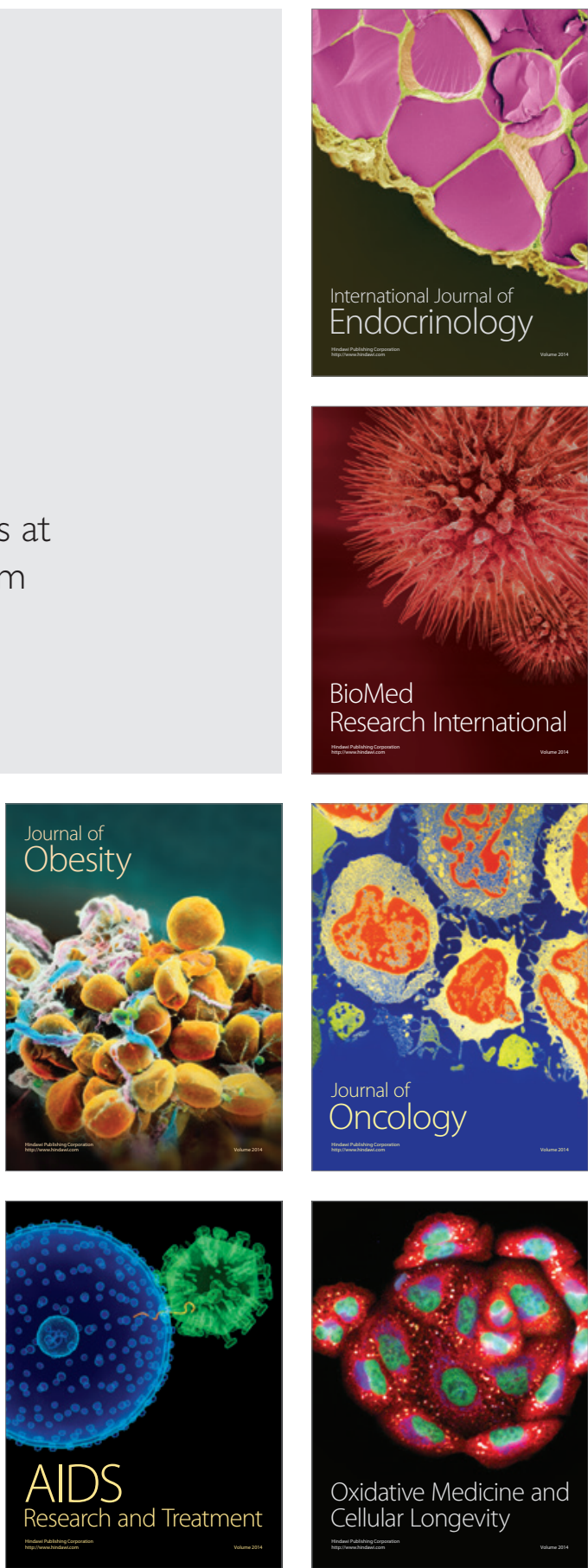